\title{
The Potential for Cellular Therapy Combined with Growth Factors in Spinal Cord Injury
}

\author{
Jack Rosner, ${ }^{1}$ Pablo Avalos, ${ }^{2}$ Frank Acosta, ${ }^{1}$ John Liu, ${ }^{1}$ and Doniel Drazin ${ }^{1}$ \\ ${ }^{1}$ Department of Neurosurgery, Cedars-Sinai Medical Center, 8363 West 3rd Street Ste 800E, Los Angeles, CA 90048, USA \\ ${ }^{2}$ Regenerative Medicine Institute, Cedars-Sinai Medical Center, Los Angeles, CA 90048, USA
}

Correspondence should be addressed to Doniel Drazin, ddrazin@gmail.com

Received 11 June 2012; Revised 19 August 2012; Accepted 28 August 2012

Academic Editor: Stefano Pluchino

Copyright ( 2012 Jack Rosner et al. This is an open access article distributed under the Creative Commons Attribution License, which permits unrestricted use, distribution, and reproduction in any medium, provided the original work is properly cited.

\begin{abstract}
Any traumatic spinal cord injury (SCI) may cause symptoms ranging from pain to complete loss of motor and sensory functions below the level of the injury. Currently, there are over 2 million SCI patients worldwide. The cost of their necessary continuing care creates a burden for the patient, their families, and society. Presently, few SCI treatments are available and none have facilitated neural regeneration and/or significant functional improvement. Research is being conducted in the following areas: pathophysiology, cellular therapies (Schwann cells, embryonic stem cells, induced pluripotent stem cells, mesenchymal stem cells, olfactory ensheathing cells), growth factors (BDNF), inhibitory molecules (NG2, myelin protein), and combination therapies (cell grafts and neurotrophins, cotransplantation). Results are often limited because of the inhibitory environment created following the injury and the limited regenerative potential of the central nervous system. Therapies that show promise in small animal models may not transfer to nonhuman primates and humans. None of the research has resulted in remarkable improvement, but many areas show promise. Studies have suggested that a combination of therapies may enhance results and may be more effective than a single therapy. This paper reviews and discusses the most promising new SCI research including combination therapies.
\end{abstract}

\section{Introduction}

Spinal cord injury (SCI) is defined as any traumatic injury to the spinal cord. Depending on the level of the spine at which it occurs and the severity of the insult, SCI may cause symptoms ranging from pain to complete loss of motor and sensory functions below the level of the injury. In the United States, incidence of SCI is approximately 40 cases per million individuals per year, resulting in about 12,000 new cases per year [1]. It is important to note that this figure does not take into account injuries that result in death prior to hospital admission and thus underestimates total incidence of SCI. Nationally and internationally, the leading cause of SCI is traffic accidents, which account for half of all injuries. Recreational activities, falls, violence, and work-related accidents account for the majority of the remainder of SCI [2].

The majority of SCIs occur in young individuals with the mean age at the time of injury at 35.3 years [2]. This young onset of lifelong debilitation results in particularly high personal and economic costs which are very high. Over the past three decades, there has been a substantial decline in mortality during the first 2 years following injury [3] and life expectancy following SCI now approaches that of the population at large [4]. Currently, there are over 2 million living survivors of SCI worldwide [5], many of which require some form of continuing care. Additionally, rehospitalization following SCI is common, with the leading causes being genitourinary, respiratory, and skin infections [6]. As of the late 1990s, the average lifetime cost of treating SCI was estimated at between $\$ 500,000$ and $\$ 2$ million per patient with total costs exceeding $\$ 7$ billion per year in the United States alone [7].

Although there are few therapies for the underlying injury, traditional management of SCI includes prevention of reinjury, treatment of secondary complications, and provision of providing rehabilitative therapy $[7,8]$. Corticosteroid treatment has been investigated as a means of controlling inflammation after SCI and thereby lessening the severity of the initial injury. Methylprednisolone administered shortly after SCI may provide a modest improvement in sensory 
and motor function below the level of the injury at followup $[9,10]$, although a number of investigators have questioned the efficacy of this intervention [11-13] and it has been suggested that further research is needed to definitively evaluate the role of corticosteroids in SCI management [14].

In recent years, a better understanding of the mechanisms underlying SCI and the introduction of tissue engineering, stem cell, growth factor, anti-inhibitory and combination therapies have led to a number of new investigatory avenues for SCI treatment. Numerous studies have suggested that, going forward, the most effective treatment for SCI may involve a combination of novel therapies $[15,16]$. In this paper, we review the most promising new treatments for SCI and suggest further investigations using combination therapies.

\section{Pathophysiology}

SCI pathophysiology can be divided into two phases. The initial injury constitutes the primary phase. During this phase, a precipitating event results in a mechanical force on the spine that causes damage to the spinal cord, resulting in the disruption and death of vasculature and neural elements. Depending on the etiology of the injury, this force may cause compression, contusion, laceration, or transection of the cord, although even in patients suffering complete paralysis, full transections are rare. Most commonly, the primary injury involves an initial contusion followed by persisting compression [2].

While the primary injury may cause observable damage to the cord, there are often no histological abnormalities immediately following SCI [17]. This suggests the importance of the secondary phase in SCI pathology. The secondary phase begins hours after the initial insult and is marked by a number of cellular and molecular changes in and around the injured area. Ongoing investigation is continuing to illuminate the underlying causes of these changes and they will not be reviewed in detail here. Some mechanisms investigated include vascular abnormalities [18], free radicals causing oxidative stress [19], and glutamate excitotoxicity [20].

Observed effects of the secondary phase include apoptosis, Wallerian degeneration, and the formation of a glial scar. Active apoptosis of oligodendrocytes resulting in demyelination and further degeneration of white and gray matter up to $13 \mathrm{~mm}$ from the lesion center has been observed to peak at 8 days and continue until at least three weeks following injury $[21,22]$. Demyelination is particularly disruptive to the ability of spinal cord neurons to transmit electrical impulses [23] and represents a significant therapeutic target.

Wallerian degeneration is another secondary process following SCI. Wallerian degeneration refers to the breakdown and demyelination of axons distal to an injury. This injury could be to a cell body or to a portion of the axon proximal to a cell body. In SCI, Wallerian degeneration is seen both above and below the level of the injury (above in dorsal columns, below in corticospinal tracts). It is not observed by MRI until 7 weeks following injury [24] and likely continues for years thereafter [25].
The secondary phase culminates in the formation of a glial "scar." A universal CNS injury response, the presence of a glial scar, has a number of implications for treatment of SCI, and thus it is helpful to understand its composition and effects. Several days after SCI, astrocytes at the edges of the lesion begin to hypertrophy and undergo a number of morphological and molecular changes. New astrocytes also appear, although their lineage is unclear [26]. One distinctive molecular change is the increased expression of glial fibrillary acidic protein (GFAP) [27], a cytoskeletal component necessary for cell growth. Over the next several weeks, these astrocytes extend overlapping processes and form a dense network of gap and tight junctions that constitute the scar [28]. Although composed primarily of astrocytes, the scar also contains oligodendrocytes, oligodendrocyte precursors, and microglia, among other cell types.

The glial scar has both beneficial and detrimental effects. By isolating the site of injury, the glial scar is instrumental in restoring the blood brain barrier, and there is also evidence that it removes excitotoxic glutamate, helps protect neural cells from oxidative stress, and stabilizes extracellular ion balance, thereby reducing the seizure threshold [26, 29]. Unfortunately, the scar also presents an impediment to axonal regrowth. In addition to acting as a physical barrier, the glial scar secretes a number of molecules that inhibit axonal sprouting, including tenascin, Semaphorin 3, and keratin and chondroitin sulfate proteoglycans (KSPGs and CSPGs) such as NG2 [30, 31].

Because the secondary response to SCI unfolds over an extended period following injury and therefore may theoretically be subject to clinical management, novel treatments for SCI have focused primarily on regulating the cellular and molecular changes that mark this phase.

\section{Biomaterials}

Tissue engineering is one strategy being explored to treat SCI. At the most basic level, polymer-based biomaterials may bridge physical gaps at the injury site, providing a substrate for neural regeneration. Features of attractive biomaterials are biocompatibility, biodegradability, and a high binding capacity. Broadly, two types of biomaterials have been tested for SCI. The first are compounds like fibrin and collagen, which are viscous and boast the ability to gel in situ, facilitating less invasive administration and conforming to the injury site [32]. The second group of compounds are premolded and designed to provide a structured scaffolding to support neural element growth. Examples of these are poly(lactic-co-glycolic acid) (PLGA) and agarose.

A number of biomaterials have been shown to promote neural growth and delay the accumulation of reactive astrocytes when implanted at a lesion site [32-34]. In addition to these histological features, some studies have also observed functional recovery in small animals treated with biomaterials alone [34]. However, there is widespread consensus that biomaterials are most promising when used as vehicles for neurotrophin delivery and scaffolding for glial cell grafts, strategies that will be discussed as combinational therapies. 


\section{Cellular Therapies}

There are three main goals of cellular therapy for SCI. Firstly, grafted cells may directly replace neural elements such as neurons or oligodendrocytes lost through primary or secondary mechanisms. Secondly, cell grafts help to fill in lesions and provide a scaffolding to support endogenous neural element growth. Lastly, grafted cells can create an environment more conducive to neuroprotection, regrowth, and remyelination. A number of cell types have been investigated for transplantation after SCI. Among these are Schwann cells (SCs) [32-37], embryonic stem cells (ESCs) $[38,39]$, mesenchymal stem cells (MSCs) [40-42], and olfactory ensheathing cells (OECs) [15, 36, 43-45].

4.1. Schwann Cells. Schwann cells normally serve to myelinate the peripheral nervous system and have long been known to be capable of remyelinating and facilitating axonal regeneration of injured spinal cord neurons $[46,47]$. Demyelination significantly impairs axonal conduction [23] and thus represents a major therapeutic target following SCI. Studies in rats have found remyelination of spinal axons following SC transplantation in several models of SCI [32-37], and axons regenerated within SC grafts are capable of conducting action potentials [48]. Modest functional improvements were reported in these same studies $[32,36]$. Additionally, SCs seem to provide effective scaffolding for both sensory and motor axonal regrowth following complete transection and also assist in remyelination in this context [37].

4.2. Embryonic Stem Cells. Embryonic stem cells (ESCs) are pluripotent cells that can be harvested from the blastocyst inner cell mass. Undifferentiated ESCs form teratomas when grafted in vivo $[49,50]$ and therefore must be induced towards a neural lineage prior to grafting. Neural differentiated ESCs transplanted into injured rat spinal cords have been found to differentiate into astrocytes, oligodendrocytes, and neurons [39] and have been associated with moderate locomotor recovery $[38,39]$. ESC-derived oligodendrocytes have been shown to assist in remyelination following chemically induced demyelination [51] and SCI [38] in the rat spinal cord.

4.3. Induced Pluripotent Stem Cells. Induced pluripotent stem cells (IPS) are becoming a widespread alternative to embryonic stem cells. IPS cells are adult somatic cells that have been reprogrammed by a combination of factors to become pluripotent and are able to generate any cell type when differentiated. IPS lines can be derived from the patient's own somatic cells. Therefore, although not wellknown, IPS cells may overcome the immunological concerns associated with cellular therapy. Another advantage to the use of IPS cells is that they can circumvent the ethical controversies that are associated with embryonic stem cells. As with ESCs, undifferentiated IPS cells form teratomas when grafted in vivo [52]. IPS-derived astrocytes have been transplanted into a rat SCI model. Although the cells were not rejected and engrafted successfully (as shown by the extension of processes), there was no evidence of functional recovery. Sensitivity to mechanical stimuli, however, was increased [52]. The lack of functional recovery may be explained by the absence of other cells types. Human and mouse IPS-derived neural progenitor cells were transplanted into a mouse SCI model and were shown to differentiate into electrophysiologically functional neurons, astrocytes and oligodendrocytes [53]. Synapse of the transplanted, neurons and host neurons was accomplished along with increased angiogenesis, remyelination, axonal regeneration, and recovery of locomotion function $[53,54]$.

4.4. Mesenchymal Stem Cells. Mesenchymal stem cells (MSCs), also referred to as bone marrow stromal cells (BMSCs), represent an attractive stem cell source because they are relatively easy to harvest, display persistent engraftment, and avoid the ethical issues associated with the harvesting of embryonic stem cells $[19,55,56]$. Additionally, MSCs have been shown in vitro to be capable of differentiating into cells exhibiting neuron morphology and several neuron-specific proteins [15], although whether these cells are able to generate action potentials is questionable [41]. It is also not clear if such differentiation can occur in vivo [42]. In animal models, MSC transplantation following SCI has been observed to promote axonal regeneration [37-39] and is associated with functional recovery [40, 41]. Human MSCs (hMSCs) have also been investigated in small animal models in anticipation of future translational research and were found to be well tolerated and to promote limited functional recovery $[57,58]$.

The mechanism of MSC-mediated regeneration is unclear. MSCs have been observed to promote the differentiation of neural stem cells (NSCs) in vitro [42], suggesting that a similar action may occur in vivo. Even the presence of unmodified MSCs in CNS tissue increases concentrations of neurotrophins including BDNF, NGF, and NT-3 in the graft site [15, 57]. Thus, it is difficult to assess MSC efficacy separately from that of neurotrophins, and it is likely that improvements in neural regeneration observed with MSCs are due at least in part to increased neurotrophin concentration.

4.5. Olfactory Ensheathing Cells. Olfactory ensheathing cells (OECs), also known as olfactory ensheathing glia (OEG), are found both centrally and peripherally along the olfactory nerve. Their candidacy for SCI repair rests largely on their observed ability to facilitate continuous neurogenesis in the inhibitory environment of the mature CNS [59]. Several trials using OEC grafts to treat SCI in rats have yielded encouraging results, with observed corticospinal axon regeneration, remyelination, and functional locomotor improvements [15, $36,43-45]$. More recently, a number of foreign trials using OECs for SCI have been conducted in humans, the largest of these involving over 300 patients in China [60], although there is concern about the methodological standards of these trials; many are poorly controlled, have not been subject to independent analysis, or use unscientific selection criteria or outcome measures [61]. Thus, few definite conclusions can be drawn from this work. 
More recent studies have cast doubt on whether the improvements observed in animal trials of OECs are direct or indirect effects of OEC engraftment. Direct remyelination was proposed as a major mechanism for the early effectiveness of OECs $[43,45,62]$; however, it has been found that OEC cultures likely contain SCs and therefore that those SCs may be the source of the observed myelination [46]. It is further hypothesized that OECs may help recruit additional endogenous SCs, further facilitating myelination, although the mechanism of this recruitment is not known [63]. Thus, the primary value of OEC transplantation may actually lie in their recruitment of SCs.

\section{Growth Factors}

Growth factor therapy has shown significant promise in the treatment of a number of CNS conditions including Alzheimer disease [64] and ischemic stroke [65]. In SCI treatment, the primary role of growth factors is to first promote neuronal survival, and, later, axonal regrowth.

A number of growth factors have been investigated to treat SCI. The most researched are brain-derived neurotrophic factor (BDNF) [66-72], nerve growth factor (NGF) [69, 73], neurotrophin-3 (NT-3) [67, 69, 70, 74], glial cell-derived neurotrophic factor (GDNF) [75], and basic fibroblast growth factor (bFGF) [73, 76, 77]. While numerous trials of growth factors for SCI have been performed in vitro and using small and, more recently, large animal models, many questions remain regarding the efficacy of these treatments and the optimal conditions for their administration.

BDNF is one of the more studied and promising growth factors for SCI therapy. In small animal models, BDNF appears to increase motor functioning shortly after injury; however, the statistical significance of this effect disappears at later followups $[66,69]$. These results point to the neuroprotective effects of BDNF immediately following injury. One possible mechanism of this neuroprotection is the recruitment of oligodendrocytes and the ensuing increase in myelination of damaged and growing axons [67], and the drop-off in improvement over control at later followups suggests that BDNF alone is not sufficient to spur axonal regrowth. Other studies, however, have demonstrated BDNF-induced axonal regrowth in the presence of a fibroblast graft, indicating that BDNF is capable of effecting such regeneration in a suitable environment $[67,72]$. Data on other growth factors is less robust but still promising (Table 1).

Interestingly, different axon systems respond to growth factors differently. Corticospinal axons-those originating in the cerebral cortex and carrying voluntary muscle movements-have in particular been generally unresponsive to therapy using a number of growth factors in both small animal and primate models [70, 75]. BDNF does appear to provide a neuroprotective effect [70] and studies have found some corticospinal axon regrowth accompanied by mild functional improvement in response to NT-3 in rats $[78,79]$.
One consideration with the use of all growth factors is the establishment of an appropriate concentration gradient. A number of studies have observed that, in the presence of neurotrophin-secreting grafts, axons will regenerate into the graft but not beyond it $[67,75]$. This might be explained by the finding that ascending neurotrophic concentration gradients guide neurite outgrowth [80], meaning that axonal growth cones may become "trapped" in neurotrophinsecreting grafts where the concentration of growth factor is higher than in the surrounding endogenous tissue. One possible solution to this problem is the use of biomaterial scaffolding containing a preexisting, immobilized concentration gradient of neurotrophins to guide neurons through the lesion, a strategy that has shown promise in vitro $[81,82]$.

Beyond neuroprotection and the stimulation of axonal growth immediately following injury, growth factor therapy may also help overcome some of the challenges presented by the mature glial scar's secretion of inhibitory factors. In the presence of NT-3, Lu et al. [74] found that axons penetrated a mature glial scar 3 months following injury and extended into an MSC-grafted lesion cavity. The authors hypothesized that regulation of neurite outgrowth may depend on the balance between inhibitors and other molecules including neurotrophins, an idea which has also been suggested by other studies examining neural growth in the presence of CSPGs [31]. Kwon et al. [72] also found atrophied rubrospinal neurons capable of regenerating into peripheral nerve grafted lesions following administration of BDNF one year following injury. Tobias et al. [71] found a similar effect with BDNF and NT-3 in a fibroblast-grafted lesion 6 weeks following injury, although the authors note that this regeneration did not compare favorably to similar treatments administered acutely.

Taken together, these studies demonstrate that growth factors function neuroprotectively immediately following injury, as well as playing an important role in neural regeneration in the mature injury site. Functional improvement is also associated with use of growth factors in some animal models, although these findings are often borderline significant and evaluated using varying metrics and therefore must be received cautiously.

\section{Inhibitory Molecules}

The presence of axonal outgrowth inhibitors also seems to play a major role in the lack of regeneration after SCI. A key obstacle in finding a successful therapy for SCI has been the presence of these inhibitory molecules following injury. The most notable molecules that have been described are NG2 [83], myelin-associated glycoprotein (MAG) [84-86], NogoA [87-90], and OMgp [91, 92]. Optimal therapy for SCI might require the inclusion, at least in part, of inhibition of these molecules.

6.1. NG2. NG2 is an inhibitory molecule that belongs to the chondroitin sulfate proteoglycan family and is expressed after CNS injuries. It is mostly expressed on the surfaces of oligodendrocytes and macrophages and has been associated with inhibition of neuronal outgrowth after SCI. Jones et al. 
TABLE 1: A review of the published studies on growth factors and spinal cord injury.

\begin{tabular}{|c|c|c|c|c|c|c|}
\hline Reference & $\begin{array}{c}\text { Model } \\
\text { (animal/injury/level) }\end{array}$ & Factor & $N$ & Graft & Histological effect & Functional effect \\
\hline Grill et al., [78] & $\begin{array}{c}\text { Rat/dorsal } \\
\text { hemisection and } \\
\text { dorsal column } \\
\text { lesion/T7 }\end{array}$ & NT3 & 21 & Fibroblast & $\begin{array}{l}\text { Corticospinal axon } \\
\text { growth }\end{array}$ & $\begin{array}{l}\text { Locomotor score } \\
\text { improvement }\end{array}$ \\
\hline Houweling et al., [66] & $\begin{array}{c}\text { Rat/partial } \\
\text { transection/T9 }\end{array}$ & BDNF & 9 & NA & None & $\begin{array}{c}\text { Locomotor score } \\
\text { improvement within } \\
1 \text { week of injury; } \\
\text { none at later } \mathrm{f} / \mathrm{u}\end{array}$ \\
\hline \multirow{4}{*}{ McTigue et al., [67] } & \multirow{4}{*}{ Rat/contusion/T8 } & NT3 & 6 & Fibroblast & $\begin{array}{l}\text { Cell growth into graft, } \\
\text { remyelination }\end{array}$ & NA \\
\hline & & $\mathrm{BDNF}$ & 12 & Fibroblast & $\begin{array}{l}\text { Cell growth into graft, } \\
\text { remyelination }\end{array}$ & NA \\
\hline & & bFGF & 5 & Fibroblast & None & NA \\
\hline & & NGF & 5 & Fibroblast & None & NA \\
\hline \multirow{2}{*}{ Lee et al., [73] } & \multirow{2}{*}{ Rat/contusion/T10 } & bFGF & 5 & NA & Reduction in necrosis & NA \\
\hline & & NGF & 5 & NA & None & NA \\
\hline Liu et al., [68] & $\begin{array}{c}\text { Rat/partial } \\
\text { hemisection/C3 }\end{array}$ & $\mathrm{BDNF}$ & 72 & Fibroblast & $\begin{array}{c}\text { Rubrospinal axon } \\
\text { regeneration }\end{array}$ & $\begin{array}{l}\text { Partial recovery of } \\
\text { forelimb function }\end{array}$ \\
\hline Rabchevsky et al., [76] & Rat/contusion/T10 & bFGF & 18 & NA & Reduction in necrosis & $\begin{array}{l}\text { Partial recovery of } \\
\text { motor function at all } \\
\text { f/u (up to } 6 \text { weeks) }\end{array}$ \\
\hline \multirow[t]{3}{*}{ Namiki et al., [69] } & \multirow[t]{3}{*}{ Rat/compression/T3 } & BDNF & 6 & NA & None & $\begin{array}{c}\text { Higher inclined plane } \\
\text { score } 1 \text { week } \\
\text { following injury; } \\
\text { none at later } \mathrm{f} / \mathrm{u}\end{array}$ \\
\hline & & NGF & 6 & NA & None & None \\
\hline & & NT3 & 6 & NA & None & None \\
\hline Rabchevsky et al., [77] & Rat/contusion/T10 & bFGF & 16 & NA & None & $\begin{array}{l}\text { Partial recovery of } \\
\text { motor function at all } \\
\text { f/u (up to } 6 \text { weeks) }\end{array}$ \\
\hline Tuszynski et al., 2002 & $\begin{array}{c}\text { Rat/dorsal } \\
\text { hemisection /T7 }\end{array}$ & NT3 & 66 & Fibroblast & $\begin{array}{c}\text { Corticospinal axon } \\
\text { growth }\end{array}$ & $\begin{array}{c}\text { Locomotor score } \\
\text { improvement }\end{array}$ \\
\hline Blesch and Tuszynski, [4] & $\begin{array}{c}\text { Rat/complete } \\
\text { transection and dorsal } \\
\text { hemisection/T7 }\end{array}$ & GDNF & 44 & Fibroblast & $\begin{array}{l}\text { Cell growth into graft, } \\
\text { remyelination }\end{array}$ & $\begin{array}{l}\text { None at } 4 \text { weeks (first } \\
\text { f/u) and beyond. }\end{array}$ \\
\hline Brock et al., [70] & $\begin{array}{l}\text { Primate/lateral } \\
\text { hemisection/C7 }\end{array}$ & $\begin{array}{l}\text { BDNF \& } \\
\text { NT3 }\end{array}$ & 7 & Fibroblast & $\begin{array}{l}\text { Neural growth into } \\
\text { graft, neuroprotection } \\
\text { of corticospinal } \\
\text { neurons }\end{array}$ & NA \\
\hline
\end{tabular}

showed that NG2 expression is upregulated within 24 hours of injury and it increases over the following two weeks after injury [93]. Studies using rat cerebellar granule neurons show that neurite growth is inhibited by the presence of NG2 even on laminin-coated surfaces by preventing neuronal cell attachment and elongation of axons [83]. The inhibitory dominance created by NG2 was further shown in a rat model of SCI where the transected CST axons were found surrounding an area of high NG2 expression [93]. Therefore, therapy focused on reducing the levels of NG2 in response to spinal cord injury may lead to improved axonal regeneration.
6.2. Myelin Proteins. Nogo-A, oligodendrocyte myelin glycoprotein (OMgp), and myelin-associated glycoprotein (MAG) are expressed by oligodendrocytes after injury to the adult CNS and are known as myelin-associated proteins (MAPs). These myelin-associated proteins are culprits that lead to inhibition of axonal regeneration by blocking axonal growth after injury [94-96]. All three MAPs bind to the Nogo-66 receptor $(\mathrm{NgR})$, a receptor that is anchored to the membrane via a glycosylphosphatidylinositol (GPI) linkage [87-91, 97]. It appears that the three proteins compete with each other for binding with the receptor $[94,98]$. Sharing of the receptor may explain why therapy targeted at a specific protein only 
has subtle effects on the axonal regeneration inhibition. However, since $\mathrm{NgR}$ is a point of convergence for the three different MAPs, it makes it an appealing target for therapy. There have been several therapies that have been studied by different groups showing efficacy in vivo.

GrandPre et al. [89] proved that using an NgR antagonist prevents inhibition by all three MAPs. Furthermore, administration of the soluble function-blocking $\mathrm{NgR}$ domain in a rat SCI model increases axonal sprouting leading to improved electrical spinal cord conduction and locomotion [97]. Infusion of the monoclonal antibody against Nogo, IN1 into the lesion site of a rat's spinal cord improves axonal outgrowth and functional recovery following SCI suggesting increased plastic and regenerative capabilities of the CNS $[85,97]$. Nevertheless, the improvements were subtle most likely due to the presence of MAG and OMgp binding to the $\operatorname{NgR}[99,100]$. MAG and Nogo-A knockout mice have been studied and have revealed that the inhibitory effects of MAG and Nogo-A, respectively, were decreased leading to improved axonal regeneration [101-103]. In the case of the Nogo-A knockout mouse, the decreased inhibitory effects were very similar to those seen with Nogo-A specific antibodies. Rho pathway inhibitors and cAMP elevation are some other therapies that have shown some efficacy in vivo [104-107]. Supplementary evidence to the benefits of antiinhibitory therapy has surfaced by the addition of antiMAG antibodies to cultures in vitro leading to a reversal of outgrowth inhibition by about 50\% [85].

The benefits seen from using anti-inhibitory therapies are vast, in particular therapies that inhibit all three proteins by blocking the NgR. Administration of anti-inhibitory therapies alone or in combination with growth factors, cellular therapy or both could be the needed solution to recovery from spinal cord injury.

\section{Combination Therapies}

Recently, there has been increasing recognition that the most promising treatment for SCI may combine a number of novel therapies that, while modestly effective individually, have an enhanced effect when used together. So-called combination therapies aim to create a neuroprotective environment, foster regeneration, and counter inhibitory factors released after CNS injury. All of these are likely required for robust regeneration following SCI. These therapies may involve neurotrophins and cell grafts $[15,108-110]$, cotransplantation of different grafts [111-113], or anti-inhibitory therapies.

7.1. Cell Grafts and Neurotrophins. Various cell grafts transduced to secrete growth factors or transplanted with exogenous growth factor administration have also shown increased efficacy versus cell grafts alone. Weidner et al. [109] investigated SCs transduced to secrete NGF in a rat model and found significantly increased neuronal growth into grafts of secreting versus nonsecreting SCs. Xu et al. [110] found that a combination of BDNF and NT-3 administered continuously following SC grafting improved neural ingrowth and myelination as compared to SC or neurotrophinonly controls. BDNF-secreting MSCs have shown promising results in a rat model. More robust neural growth was observed into grafts of MSCs induced to secrete BDNF versus control MSCs, although how this effect compares to treatment with only BDNF was not part of the study design [114]. Another study found that SCs transduced to secrete D15A, a neurotrophin that mimics NT-3 and BDNF, engendered more robust regeneration (greater graft volume, increased myelination, greater axon length) when compared to unmodified SC grafts [108].

7.2. Cotransplantation. Grafts employing combinations of cell types also appear advantageous over single-cell-type grafts. Pearse et al. [112] investigated a combination of SCs and OECs and reported significantly greater functional improvement in SC and OEG graft subjects versus controls and only SC or OEC graft subjects. Deng et al. [111] found that cotransplantation of MSCs with OECs in a rat model resulted in greater functional improvement versus either cell type alone. The authors suggest one possible reason for this was that the OECs had a positive effect on MSC survival and neural differentiation. Zeng et al. [113] have proposed a similar mechanism to explain the finding that SCs transplanted with neural stem cells lead to increased neural stem cell growth and differentiation.

7.3. Biomaterials with Neurotrophins and Cell Grafts. Frequently, biomaterial scaffolding has been used in conjunction with other regenerative and anti-inhibitory treatments, such as neurotrophin administration [115-119] and glial cell grafts $[120,121]$.

Two significant problems with the use of growth factors to treat SCI have been the maintenance of adequate concentrations following administration and the establishment of an appropriate concentration gradient for directed neural outgrowth. Scaffolding strategies offer promising solutions to these problems. Through sustained release mechanisms such as heparin-based delivery systems (HBDSs), several groups have had success establishing the diffusion- and cellmediated release of neurotrophins. Taylor et al. $[117,118]$ tested an NT-3 secreting fibrin gel using a HBDS administrated immediately after injury and found significantly increased neuronal sprouting compared to non-HBDS NT-3 fibrin and fibrin only controls. Similarly, rats treated with collagen-bound BDNF (facilitating sustained delivery) displayed significant nerve fiber growth and functional improvement over use of the scaffold alone [115].

Other studies have incorporated neurotrophins into rigid scaffolds designed to guide axonal growth. When BDNF was incorporated into the walls and lumen of a freeze-dried agarose scaffold and implanted following SCI, axons were observed to grow through individual small-diameter channels, suggesting the ability of properly organized biomaterials to support a tract-like axonal layout similar to that within the uninjured spinal cord [116]. Beyond direct implantation in the scaffold, other methods of neurotrophin delivery are being explored. Tuinstra et al. [119] investigated the use of lentiviral vectors encoding NT-3 and BDNF delivered through multichannel PLGA scaffolds in a rat hemisection 


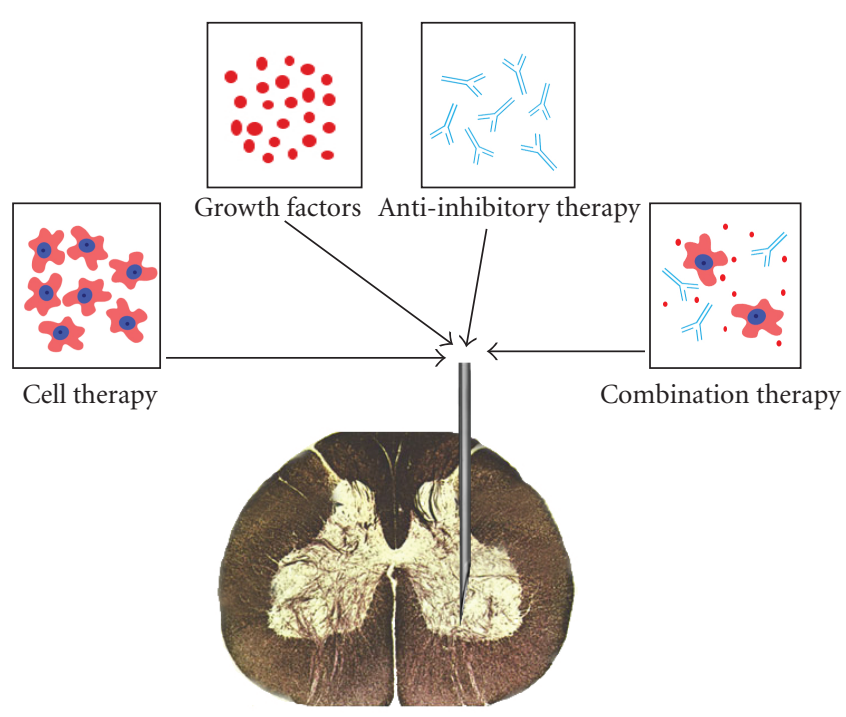

FIgURE 1: The individual and combination therapies currently being studied which show great promise.

model. Compared to empty scaffolds, scaffolds with vectors had significantly more axons per channel with enhanced myelination. This is consistent with the observed effects of NT-3 and BDNF, suggesting the efficacy of this unique delivery method.

The injured spinal cord appears responsive to such biomaterial-neurotrophin therapies even when there is a significant delay to treatment. Johnson et al. [122] found that rats treated with an NT-3 releasing fibrin scaffold 2 weeks after the initial insult showed an increase in neural fiber density and a decrease in astrocyte accumulation, although this study did not investigate functional recovery.

Biomaterials have also shown promise when used to enhance cellular therapies. Hemisected rats injected with a fibrin matrix containing BMSCs had significantly greater functional recovery at up to 4 weeks (endpoint) following transplantation than those treated with fibrin or BMSCs alone. Histological analysis further revealed enhanced survival and migration of fibrin-bound BMSCs versus those injected alone [120]. Highly organized scaffold designs have also shown promise when used with cell grafts. Teng et al. [121] investigated a PLGA scaffold seeded with NSCs in a rat hemisection model. The scaffold contained a core designed to facilitate axonal growth and an outer portion designed to allow fluid transport while inhibiting scar tissue growth. The most significant axonal growth and functional improvement were noted in the seeded scaffold group, although the presence of an empty scaffold also facilitated some improvement over control. The authors hypothesize that the major contribution of the NSCs was to provide trophic support to existing neural elements rather than replacing them directly, as most NSCs remained undifferentiated.

In short, studies to date indicate that combination therapies pose no additional dangers over their constituent interventions and seem to be, theoretically, more efficacious (Figure 1). Although, more studies are required, the authors believe that the best combination therapy could be a biomatrix scaffold, with sustained release of neurotrophic factors (BDNF and NT-3), which is seeded with a cellular graft. The cell type choice is still undetermined due to the lack of studies determining a clear benefit from one cellular type to another.

\section{Conclusion}

Facilitating significant neural regeneration and ensuing functional improvement following spinal cord injury remains a challenging goal. Because of the inhibitory environment created following CNS injury including SCI and the intrinsically limited regenerative potential of the CNS (e.g., the insufficient expression of regeneration associated genes such as those coding for cytoskeletal proteins) [123], strategies to regenerate neurons and other neural elements face a twofold challenge.

There is also still a great deal of uncertainty regarding how therapies investigated thus far primarily in small animal models will transfer to nonhuman primates and, eventually, humans. While some preliminary trials have been conducted, they are either poorly reported or have not lead to remarkable improvement. Nevertheless, there is certainly reason to be optimistic regarding the possibility of combining new therapeutic approaches for SCI.

\section{Acknowledgment}

The authors wish to thank the Robert and Louise Schwab Fund for their continued support.

\section{References}

[1] V. W. Lin, C. M. Bono, D. D. Cardenas et al., "Epidemiology of spinal cord injury," in Spinal Cord Medicine: Principles and Practice, chapter 4, Demos Medical, LLC, 2010. 
[2] L. H. S. Sekhon and M. G. Fehlings, "Epidemiology, demographics, and pathophysiology of acute spinal cord injury," Spine, vol. 26, no. 24, pp. S2-S12, 2001.

[3] D. J. Strauss, M. J. DeVivo, D. R. Paculdo, and R. M. Shavelle, "Trends in life expectancy after spinal cord injury," Archives of Physical Medicine and Rehabilitation, vol. 87, no. 8, pp. 10791085, 2006.

[4] A. Blesch and M. H. Tuszynski, "Cellular GDNF delivery promotes growth of motor and dorsal column sensory axons after partial and complete spinal cord transections and induces remyelination," Journal of Comparative Neurology, vol. 467, no. 3, pp. 403-417, 2003.

[5] J. W. Fawcett, A. Curt, J. D. Steeves et al., "Guidelines for the conduct of clinical trials for spinal cord injury as developed by the ICCP panel: spontaneous recovery after spinal cord injury and statistical power needed for therapeutic clinical trials," Spinal Cord, vol. 45, no. 3, pp. 190-205, 2007.

[6] D. D. Cardenas, J. M. Hoffman, S. Kirshblum, and W. McKinley, "Etiology and incidence of rehospitalization after traumatic spinal cord injury: a multicenter analysis," Archives of Physical Medicine and Rehabilitation, vol. 85, no. 11, pp. 1757-1763, 2004.

[7] J. W. McDonald and C. Sadowsky, "Spinal-cord injury," The Lancet, vol. 359, no. 9304, pp. 417-425, 2002.

[8] V. R. Edgerton, S. J. Kim, R. M. Ichiyama, Y. P. Gerasimenko, and R. R. Roy, "Rehabilitative therapies after spinal cord injury," Journal of Neurotrauma, vol. 23, no. 3-4, pp. 560-570, 2006.

[9] M. B. Bracken, M. J. Shepard, W. F. Collins et al., "A randomized, controlled trial of methylprednisolone or naloxone in the treatment of acute spinal-cord injury. Results of the Second National Acute Spinal Cord Injury Study," The New England Journal of Medicine, vol. 322, no. 20, pp. 1405-1411, 1990.

[10] M. B. Bracken, M. J. Shepard, T. R. Holford et al., "Administration of methylprednisolone for 24 or 48 hours or tirilazad mesylate for 48 hours in the treatment of acute spinal cord injury: results of the Third National Acute Spinal Cord Injury randomized controlled trial," Journal of the American Medical Association, vol. 277, no. 20, pp. 1597-1604, 1997.

[11] R. J. Hurlbert, "Methylprednisolone for acute spinal cord injury an inappropriate standard of care," Journal of Neurosurgery, vol. 93, no. 1, pp. 1-7, 2000.

[12] F. T. Sayer, E. Kronvall, and O. G. Nilsson, "Methylprednisolone treatment in acute spinal cord injury: the myth challenged through a structured analysis of published literature," Spine Journal, vol. 6, no. 3, pp. 335-343, 2006.

[13] D. J. Short, W. S. El Masry, and P. W. Jones, "High dose methylprednisolone in the management of acute spinal cord injury-a systematic review from a clinical perspective," Spinal Cord, vol. 38, no. 5, pp. 273-286, 2000.

[14] I. Rozet, "Methylprednisolone in acute spinal cord injury: is there any other ethical choice?" Journal of Neurosurgical Anesthesiology, vol. 20, no. 2, pp. 137-139, 2008.

[15] J. Lu, F. Féron, S. M. Ho, A. Mackay-Sim, and P. M. E. Waite, "Transplantation of nasal olfactory tissue promotes partial recovery in paraplegic adult rats," Brain Research, vol. 889, no. 1-2, pp. 344-357, 2001.

[16] S. Thuret, L. D. F. Moon, and F. H. Gage, "Therapeutic interventions after spinal cord injury," Nature Reviews Neuroscience, vol. 7, no. 8, pp. 628-643, 2006.

[17] M. D. Norenberg, J. Smith, and A. Marcillo, "The pathology of human spinal cord injury: defining the problems," Journal of Neurotrauma, vol. 21, no. 4, pp. 429-440, 2004.
[18] C. H. Tator and I. Koyanagi, "Vascular mechanisms in the pathophysiology of human spinal cord injury," Journal of Neurosurgery, vol. 86, no. 3, pp. 483-492, 1997.

[19] Y. Jiang, B. N. Jahagirdar, R. L. Reinhardt et al., "Pluripotency of mesenchymal stem cells derived from adult marrow," Nature, vol. 418, no. 6893, pp. 41-49, 2002.

[20] E. Park, A. A. Velumian, and M. G. Fehlings, "The role of excitotoxicity in secondary mechanisms of spinal cord injury: a review with an emphasis on the implications for white matter degeneration," Journal of Neurotrauma, vol. 21, no. 6, pp. 754-774, 2004.

[21] M. J. Crowe, J. C. Bresnahan, S. L. Shuman, J. N. Masters, and M. S. Beattie, "Apoptosis and delayed degeneration after spinal cord injury in rats and monkeys," Nature Medicine, vol. 3, pp. 73-76, 1997.

[22] E. Emery, P. Aldana, M. B. Bunge et al., "Apoptosis after traumatic human spinal cord injury," Journal of Neurosurgery, vol. 89, no. 6, pp. 911-920, 1998.

[23] W. I. Mcdonald and T. A. Sears, "The effects of experimental demyelination on conduction in the central nervous system," Brain, vol. 93, no. 3, pp. 583-598, 1970.

[24] J. L. Becerra, W. R. Puckett, E. D. Hiester et al., "MRpathologic comparisons of wallerian degeneration in spinal cord injury," American Journal of Neuroradiology, vol. 16, no. 1, pp. 125-133, 1995.

[25] A. Buss, K. Pech, D. Merkler et al., "Sequential loss of myelin proteins during Wallerian degeneration in the human spinal cord," Brain, vol. 128, no. 2, pp. 356-364, 2005.

[26] M. V. Sofroniew, "Molecular dissection of reactive astrogliosis and glial scar formation," Trends in Neurosciences, vol. 32, no. 12, pp. 638-647, 2009.

[27] M. Eddelston and L. Mucke, "Molecular profile of reactive astrocytes-implications for their role in neurologic disease," Neuroscience, vol. 54, no. 1, pp. 15-36, 1993.

[28] J. W. Fawcett and R. A. Asher, "The glial scar and central nervous system repair," Brain Research Bulletin, vol. 49, no. 6, pp. 377-391, 1999.

[29] T. G. Bush, N. Puvanachandra, C. H. Horner et al., "Leukocyte infiltration, neuronal degeneration, and neurite outgrowth after ablation of scar-forming, reactive astrocytes in adult transgenic mice," Neuron, vol. 23, no. 2, pp. 297-308, 1999.

[30] M. T. Fitch and J. Silver, "CNS injury, glial scars, and inflammation: inhibitory extracellular matrices and regeneration failure," Experimental Neurology, vol. 209, no. 2, pp. 294-301, 2008.

[31] J. Silver and J. H. Miller, "Regeneration beyond the glial scar," Nature Reviews Neuroscience, vol. 5, no. 2, pp. 146-156, 2004.

[32] V. R. King, A. Alovskaya, D. Y. T. Wei, R. A. Brown, and J. V. Priestley, "The use of injectable forms of fibrin and fibronectin to support axonal ingrowth after spinal cord injury," Biomaterials, vol. 31, no. 15, pp. 4447-4456, 2010.

[33] P. J. Johnson, S. R. Parker, and S. E. Sakiyama-Elbert, "Fibrinbased tissue engineering scaffolds enhance neural fiber sprouting and delay the accumulation of reactive astrocytes at the lesion in a subacute model of spinal cord injury," Journal of Biomedical Materials Research A, vol. 92, no. 1, pp. 152163, 2010.

[34] S. Yoshii, S. Ito, M. Shima, A. Taniguchi, and M. Akagi, "Functional restoration of rabbit spinal cord using collagenfilament scaffold," Journal of Tissue Engineering and Regenerative Medicine, vol. 3, no. 1, pp. 19-25, 2009. 
[35] M. Firouzi, P. Moshayedi, H. Saberi et al., "Transplantation of Schwann cells to subarachnoid space induces repair in contused rat spinal cord," Neuroscience Letters, vol. 402, no. 1-2, pp. 66-70, 2006.

[36] T. Takami, M. Oudega, M. L. Bates, P. M. Wood, N. Kleitman, and M. B. Bunge, "Schwann cell but not olfactory ensheathing glia transplants improve hindlimb locomotor performance in the moderately contused adult rat thoracic spinal cord," Journal of Neuroscience, vol. 22, no. 15, pp. 6670-6681, 2002.

[37] X. M. Xu, A. Chen, V. Guénard, N. Kleitman, and M. B. Bunge, "Bridging Schwann cell transplants promote axonal regeneration from both the rostral and caudal stumps of transected adult rat spinal cord," Brain Cell Biology, vol. 26, no. 1, pp. 1-16, 1997.

[38] H. S. Keirstead, G. Nistor, G. Bernal et al., "Human embryonic stem cell-derived oligodendrocyte progenitor cell transplants remyelinate and restore locomotion after spinal cord injury," Journal of Neuroscience, vol. 25, no. 19, pp. 4694-4705, 2005.

[39] J. W. Mcdonald, X. Z. Liu, Y. Qu et al., "Transplanted embryonic stem cells survive, differentiate and promote recovery in injured rat spinal cord," Nature Medicine, vol. 5, no. 12, pp. 1410-1412, 1999.

[40] M. Chopp, X. H. Zhang, Y. Li et al., "Spinal cord injury in rat: treatment with bone marrow stromal cell transplantation," NeuroReport, vol. 11, no. 13, pp. 3001-3005, 2000.

[41] C. P. Hofstetter, E. J. Schwarz, D. Hess et al., "Marrow stromal cells form guiding strands in the injured spinal cord and promote recovery," Proceedings of the National Academy of Sciences of the United States of America, vol. 99, no. 4, pp. 2199-2204, 2002.

[42] S. Wu, Y. Suzuki, Y. Ejiri et al., "Bone marrow stromal cells enhance differentiation of cocultured neurosphere cells and promote regeneration of injured spinal cord," Journal of Neuroscience Research, vol. 72, no. 3, pp. 343-351, 2003.

[43] Y. Li, P. M. Field, and G. Raisman, "Repair of adult rat corticospinal tract by transplants of olfactory ensheathing cells," Science, vol. 277, no. 5334, pp. 2000-2002, 1997.

[44] A. Ramón-Cueto, M. I. Cordero, F. F. Santos-Benito, and J. Avila, "Functional recovery of paraplegic rats and motor axon regeneration in their spinal cords by olfactory ensheathing glia," Neuron, vol. 25, no. 2, pp. 425-435, 2000.

[45] A. Ramón-Cueto, G. W. Plant, J. Avila, and M. B. Bunge, "Long-distance axonal regeneration in the transected adult rat spinal cord is promoted by olfactory ensheathing glia transplants," Journal of Neuroscience, vol. 18, no. 10, pp. 3803-3815, 1998.

[46] W. F. Blakemore, "Remyelination by Schwann cells of axons demyelinated by intraspinal injection of 6 aminonicotinamide in the rat," Journal of Neurocytology, vol. 4, no. 6, pp. 745-757, 1975.

[47] W. F. Blakemore, "Invasion of Schwann cells into the spinal cord of the rat following local injections of lysolecithin," Neuropathology and Applied Neurobiology, vol. 2, no. 1, pp. 21-39, 1976.

[48] A. Pinzon, B. Calancie, M. Oudega, and B. R. Noga E, "Conduction of impulses by axons regenerated in a Schwann cell graft in the transected adult rat thoracic spinal cord," Journal of Neuroscience Research, vol. 64, no. 5, pp. 533-541, 2001.

[49] B. E. Reubinoff, M. F. Pera, C. Y. Fong, A. Trounson, and A. Bongso, "Embryonic stem cell lines from human blastocysts: somatic differentiation in vitro," Nature Biotechnology, vol. 18, no. 4, pp. 399-404, 2000.

[50] J. A. Thomson, "Embryonic stem cell lines derived from human blastocysts," Science, vol. 282, no. 5391, pp. 11451147, 1998.

[51] S. Liu, Y. Qu, T. J. Stewart et al., "Embryonic stem cells differentiate into oligodendrocytes and myelinate in culture and after spinal cord transplantation," Proceedings of the National Academy of Sciences of the United States of America, vol. 97, no. 11, pp. 6126-6131, 2000.

[52] S. Yamanaka, "A Fresh Look at iPS Cells," Cell, vol. 137, no. 1, pp. 13-17, 2009.

[53] O. Tsuji, K. Miura, Y. Okada et al., "Therapeutic potential of appropriately evaluated safe-induced pluripotent stem cells for spinal cord injury," Proceedings of the National Academy of Sciences of the United States of America, vol. 107, pp. 1270412709, 2010.

[54] S. Nori, Y. Okada, A. Yasuda et al., "Grafted human-induced pluripotent stem-cell-derived neurospheres promote motor functional recovery after spinal cord injury in mice," Proceedings of the National Academy of Sciences of the United States of America, vol. 108, pp. 16825-16830, 2011.

[55] M. S. Frankel, "In search of stem cell policy," Science, vol. 287, no. 5457, p. 1397, 2000.

[56] A. McLaren, "Ethical and social considerations of stem cell research,” Nature, vol. 414, no. 6859, pp. 129-131, 2001.

[57] D. Čížková, J. Rosocha, I. Vanický, S. Jergová, and M. Čížek, "Transplants of human mesenchymal stem cells improve functional recovery after spinal cord injury in the rat," Cellular and Molecular Neurobiology, vol. 26, no. 7-8, pp. 1167-1180, 2006.

[58] E. Mansilla, G. H. Marin, F. Sturla et al., "Human mesenchymal stem cells are tolerized by mice and improve skin and spinal cord injuries," Transplantation Proceedings, vol. 37, no. 1, pp. 292-294, 2005.

[59] R. Doucette, "Glial influences on axonal growth in the primary olfactory system," GLIA, vol. 3, no. 6, pp. 433-449, 1990.

[60] B. H. Dobkin, A. Curt, and J. Guest, "Cellular transplants in China: observational study from the largest human experiment in chronic spinal cord injury," Neurorehabilitation and Neural Repair, vol. 20, no. 1, pp. 5-13, 2006.

[61] G. W. Hawryluk, J. Rowland, B. K. Kwon, and M. G. Fehlings, "Protection and repair of the injured spinal cord: a review of completed, ongoing, and planned clinical trials for acute spinal cord injury," Neurosurgical Focus, vol. 25, no. 5, article E14, 2008.

[62] T. Imaizumi, K. L. Lankford, S. G. Waxman, C. A. Greer, and J. D. Kocsis, "Transplanted olfactory ensheathing cells remyelinate and enhance axonal conduction in the demyelinated dorsal columns of the rat spinal cord," Journal of Neuroscience, vol. 18, no. 16, pp. 6176-6185, 1998.

[63] J. G. Boyd, R. Doucette, and M. D. Kawaja, "Defining the role of olfactory ensheathing cells in facilitating axon remyelination following damage to the spinal cord," FASEB Journal, vol. 19, no. 7, pp. 694-703, 2005.

[64] M. H. Tuszynski, L. Thal, M. Pay et al., "A phase 1 clinical trial of nerve growth factor gene therapy for Alzheimer disease," Nature Medicine, vol. 11, no. 5, pp. 551-555, 2005.

[65] L. R. Zhao, W. M. Duan, M. Reyes, C. D. Keene, C. M. Verfaillie, and W. C. Low, "Human bone marrow stem cells exhibit neural phenotypes and ameliorate neurological 
deficits after grafting into the ischemic brain of rats," Experimental Neurology, vol. 174, no. 1, pp. 11-20, 2002.

[66] D. A. Houweling, J. T. H. Van Asseldonk, A. J. Lankhorst et al., "Local application of collagen containing brain-derived neurotrophic factor decreases the loss of function after spinal cord injury in the adult rat," Neuroscience Letters, vol. 251, no. 3, pp. 193-196, 1998.

[67] D. M. McTigue, P. J. Horner, B. T. Stokes, and F. H. Gage, "Neurotrophin-3 and brain-derived neurotrophic factor induce oligodendrocyte proliferation and myelination of regenerating axons in the contused adult rat spinal cord," Journal of Neuroscience, vol. 18, no. 14, pp. 5354-5365, 1998.

[68] Y. Liu, D. Kim, B. T. Himes et al., "Transplants of fibroblasts genetically modified to express BDNF promote regeneration of adult rat rubrospinal axons and recovery of forelimb function," Journal of Neuroscience, vol. 19, no. 11, pp. 43704387, 1999.

[69] J. Namiki, A. Kojima, and C. H. Tator, "Effect of brainderived neurotrophic factor, nerve growth factor, and neurotrophin-3 on functional recovery and regeneration after spinal cord injury in adult rats," Journal of Neurotrauma, vol. 17, no. 12, pp. 1219-1231, 2000.

[70] J. H. Brock, E. S. Rosenzweig, A. Blesch et al., "Local and remote growth factor effects after primate spinal cord injury," Journal of Neuroscience, vol. 30, no. 29, pp. 9728-9737, 2010.

[71] C. A. Tobias, J. S. Shumsky, M. Shibata et al., "Delayed grafting of BDNF and NT-3 producing fibroblasts into the injured spinal cord stimulates sprouting, partially rescues axotomized red nucleus neurons from loss and atrophy, and provides limited regeneration," Experimental Neurology, vol. 184, no. 1, pp. 97-113, 2003.

[72] B. K. Kwon, J. Liu, C. Messerer et al., "Survival and regeneration of rubrospinal neurons 1 year after spinal cord injury," Proceedings of the National Academy of Sciences of the United States of America, vol. 99, no. 5, pp. 3246-3251, 2002.

[73] T. T. Lee, B. A. Green, W. D. Dietrich, and R. P. Yezierski, "Neuroprotective effects of basic fibroblast growth factor following spinal cord contusion injury in the rat," Journal of Neurotrauma, vol. 16, no. 5, pp. 347-356, 1999.

[74] P. Lu, L. L. Jones, and M. H. Tuszynski, "Axon regeneration through scars and into sites of chronic spinal cord injury," Experimental Neurology, vol. 203, no. 1, pp. 8-21, 2007.

[75] A. Blesch and M. H. Tuszynski, "Cellular GDNF delivery promotes growth of motor and dorsal column sensory axons after partial and complete spinal cord transections and induces remyelination," Journal of Comparative Neurology, vol. 467, no. 3, pp. 403-417, 2003.

[76] A. G. Rabchevsky, I. Fugaccia, A. Fletcher-Turner, D. A. Blades, M. P. Mattson, and S. W. Scheff, "Basic fibroblast growth factor (bFGF) enhances tissue sparing and functional recovery following moderate spinal cord injury," Journal of Neurotrauma, vol. 16, no. 9, pp. 817-830, 1999.

[77] A. G. Rabchevsky, I. Fugaccia, A. F. Turner, D. A. Blades, M. P. Mattson, and S. W. Scheff, "Basic fibroblast growth factor (bFGF) enhances functional recovery following severe spinal cord injury to the rat," Experimental Neurology, vol. 164, no. 2, pp. 280-291, 2000.

[78] R. Grill, K. Murai, A. Blesch, F. H. Gage, and M. H. Tuszynski, "Cellular delivery of neurotrophin-3 promotes corticospinal axonal growth and partial functional recovery after spinal cord injury," The Journal of Neuroscience, vol. 17, no. 14, pp. 5560-5572, 1997.
[79] M. H. Tuszynski, R. Grill, L. L. Jones et al., "NT-3 gene delivery elicits growth of chronically injured corticospinal axons and modestly improves functional deficits after chronic scar resection," Experimental Neurology, vol. 181, no. 1, pp. 47-56, 2003.

[80] X. Cao and M. S. Shoichet, "Defining the concentration gradient of nerve growth factor for guided neurite outgrowth," Neuroscience, vol. 103, no. 3, pp. 831-840, 2001.

[81] T. A. Kapur and M. S. Shoichet, "Immobilized concentration gradients of nerve growth factor guide neurite outgrowth," Journal of Biomedical Materials Research A, vol. 68, no. 2, pp. 235-243, 2004.

[82] K. Moore, M. Macsween, and M. Shoichet, "Immobilized concentration gradients of neurotrophic factors guide neurite outgrowth of primary neurons in macroporous scaffolds," Tissue Engineering, vol. 12, no. 2, pp. 267-278, 2006.

[83] C. L. Dou and J. M. Levine, "Inhibition of neurite growth by the NG2 chondroitin sulfate proteoglycan," Journal of Neuroscience, vol. 14, no. 12, pp. 7616-7628, 1994.

[84] L. McKerracher, S. David, D. L. Jackson, V. Kottis, R. J. Dunn, and P. E. Braun, "Identification of myelin-associated glycoprotein as a major myelin-derived inhibitor of neurite growth," Neuron, vol. 13, no. 4, pp. 805-811, 1994.

[85] G. Mukhopadhyay, P. Doherty, F. S. Walsh, P. R. Crocker, and M. T. Filbin, "A novel role for myelin-associated glycoprotein as an inhibitor of axonal regeneration," Neuron, vol. 13, no. 3, pp. 757-767, 1994.

[86] B. P. Liu, A. Fournier, T. GrandPre, and S. M. Strittmatter, "Myelin-associated glycoprotein as a functional ligand for the Nogo-66 receptor," Science, vol. 297, no. 5584, pp. 1190 1193, 2002.

[87] A. E. Fournier, T. GrandPre, and S. M. Strittmatter, "Identification of a receptor mediating Nogo-66 inhibition of axonal regeneration," Nature, vol. 409, no. 6818, pp. 341-346, 2001.

[88] M. S. Chen, A. B. Huber, M. E. D. van der Haar et al., "NogoA is a myelin-associated neurite outgrowth inhibitor and an antigen for monoclonal antibody IN-1," Nature, vol. 403, no. 6768, pp. 434-439, 2000.

[89] T. GrandPre, F. Nakamura, T. Vartanlan, and S. M. Strittmatter, "Identification of the Nogo inhibitor of axon regeneration as a Reticulon protein," Nature, vol. 403, no. 6768, pp. 439-444, 2000.

[90] R. Prinjha, S. E. Moore, M. Vinson et al., "Inhibitor of neurite outgrowth in humans," Nature, vol. 403, no. 6768, pp. 383$384,2000$.

[91] K. C. Wang, V. Koprivica, J. A. Kim et al., "Oligodendrocytemyelin glycoprotein is a Nogo receptor ligand that inhibits neurite outgrowth," Nature, vol. 417, no. 6892, pp. 941-944, 2002.

[92] S. M. Curristin, A. Cao, W. B. Stewart et al., "Disrupted synaptic development in the hypoxic newborn brain," Proceedings of the National Academy of Sciences of the United States of America, vol. 99, no. 24, pp. 15729-15734, 2002.

[93] L. L. Jones, Y. Yamaguchi, W. B. Stallcup, and M. H. Tuszynski, "NG2 is a major chondroitin sulfate proteoglycan produced after spinal cord injury and is expressed by macrophages and oligodendrocyte progenitors," Journal of Neuroscience, vol. 22, no. 7, pp. 2792-2803, 2002.

[94] M. Domeniconi, Z. Cao, T. Spencer et al., "Myelin-associated glycoprotein interacts with the Nogo66 receptor to inhibit neurite outgrowth," Neuron, vol. 35, no. 2, pp. 283-290, 2002. 
[95] J. Qiu, D. Cai, and M.T. Filbin, "Glial inhibition of nerve regeneration in the mature mammalian CNS," Glia, vol. 29, pp. 166-174, 2000.

[96] M. E. Schwab and D. Bartholdi, "Degeneration and regeneration of axons in the lesioned spinal cord," Physiological Reviews, vol. 76, no. 2, pp. 319-370, 1996.

[97] S. Li, B. P. Liu, S. Budel et al., "Blockade of Nogo-66, myelin-associated glycoprotein, and oligodendrocyte myelin glycoprotein by soluble Nogo-66 receptor promotes axonal sprouting and recovery after spinal injury," Journal of Neuroscience, vol. 24, no. 46, pp. 10511-10520, 2004.

[98] M. E. Schwab, "Nogo and axon regeneration," Current Opinion in Neurobiology, vol. 14, no. 1, pp. 118-124, 2004.

[99] L. Schnell and M. E. Schwab, "Axonal regeneration in the rat spinal cord produced by an antibody against myelinassociated neurite growth inhibitors," Nature, vol. 343, no. 6255, pp. 269-272, 1990.

[100] L. Schnell and M. E. Schwab, "Sprouting and regeneration of lesioned corticospinal tract fibres in the adult rat spinal cord," European Journal of Neuroscience, vol. 5, no. 9, pp. 11561171, 1993.

[101] M. Simonen, V. Pedersen, O. Weinmann et al., "Systemic deletion of the myelin-associated outgrowth inhibitor NogoA improves regenerative and plastic responses after spinal cord injury," Neuron, vol. 38, no. 2, pp. 201-211, 2003.

[102] D. Montag, K. P. Giese, U. Bartsch et al., "Mice deficient for the myelin-associated glycoprotein show subtle abnormalities in myelin," Neuron, vol. 13, no. 1, pp. 229-246, 1994.

[103] M. Li, A. Shibata, C. Li et al., "Myelin-associated glycoprotein inhibits neurite/axon growth and causes growth cone collapse," Journal of Neuroscience Research, vol. 46, pp. 404414, 1996.

[104] P. Dergham, B. Ellezam, C. Essagian, H. Avedissian, W. D. Lubell, and L. McKerracher, "Rho signaling pathway targeted to promote spinal cord repair," Journal of Neuroscience, vol. 22, no. 15, pp. 6570-6577, 2002.

[105] A. E. Fournier, B. T. Takizawa, and S. M. Strittmatter, "Rho kinase inhibition enhances axonal regeneration in the injured CNS," Journal of Neuroscience, vol. 23, no. 4, pp. 1416-1423, 2003.

[106] S. Neumann, F. Bradke, M. Tessier-Lavigne, and A. I. Basbaum, "Regeneration of sensory axons within the injured spinal cord induced by intraganglionic cAMP elevation," Neuron, vol. 34, no. 6, pp. 885-893, 2002.

[107] J. Qiu, D. Cai, H. Dai et al., "Spinal axon regeneration induced by elevation of cyclic AMP," Neuron, vol. 34, no. 6, pp. 895-903, 2002.

[108] K. L. Golden, D. D. Pearse, B. Blits et al., "Transduced Schwann cells promote axon growth and myelination after spinal cord injury," Experimental Neurology, vol. 207, no. 2, pp. 203-217, 2007.

[109] N. Weidner, A. Blesch, R. J. Grill, and M. H. Tuszynski, "Nerve growth factor-hypersecreting schwann cell grafts augment and guide spinal cord axonal growth and remyelinate central nervous system axons in a phenotypically appropriate manner that correlates with expression of L1," The Journal of Comparative Neurology, vol. 413, pp. 495-506, 1999.

[110] X. M. Xu, V. Guenard, N. Kleitman, P. Aebischer, and M. B. Bunge, "A combination of BDNF and NT-3 promotes supraspinal axonal regeneration into Schwann cell grafts in adult rat thoracic spinal cord," Experimental Neurology, vol. 134, no. 2, pp. 261-272, 1995.
[111] Y. B. Deng, Y. Liu, W. B. Zhu et al., "The co-transplantation of human bone marrow stromal cells and embryo olfactory ensheathing cells as a new approach to treat spinal cord injury in a rat model," Cytotherapy, vol. 10, no. 6, pp. 551-564, 2008.

[112] D. D. Pearse, A. R. Sanchez, F. C. Pereira et al., "Transplantation of Schwann cells and/or olfactory ensheathing glia into the contused spinal cord: survival, migration, axon association, and functional recovery," GLIA, vol. 55, no. 9, pp. 976-1000, 2007.

[113] Y. S. Zeng, Y. Ding, L. Z. Wu et al., "Co-transplantation of Schwann cells promotes the survival and differentiation of neural stem cells transplanted into the injured spinal cord," Developmental Neuroscience, vol. 27, no. 1, pp. 20-26, 2005.

[114] P. Lu, L. L. Jones, and M. H. Tuszynski, "BDNF-expressing marrow stromal cells support extensive axonal growth at sites of spinal cord injury," Experimental Neurology, vol. 191, no. 2, pp. 344-360, 2005.

[115] Q. Han, W. Sun, H. Lin et al., "Linear ordered collagen scaffolds loaded with collagen-binding brain-derived neurotrophic factor improve the recovery of spinal cord injury in rats," Tissue Engineering A, vol. 15, no. 10, pp. 2927-2935, 2009.

[116] S. Stokols and M. H. Tuszynski, "Freeze-dried agarose scaffolds with uniaxial channels stimulate and guide linear axonal growth following spinal cord injury," Biomaterials, vol. 27, no. 3, pp. 443-451, 2006.

[117] S. J. Taylor, J. W. McDonald, and S. E. Sakiyama-Elbert, "Controlled release of neurotrophin-3 from fibrin gels for spinal cord injury," Journal of Controlled Release, vol. 98, no. 2, pp. 281-294, 2004.

[118] S. J. Taylor, E. S. Rosenzweig, J. W. McDonald, and S. E. Sakiyama-Elbert, "Delivery of neurotrophin-3 from fibrin enhances neuronal fiber sprouting after spinal cord injury," Journal of Controlled Release, vol. 113, no. 3, pp. 226-235, 2006.

[119] H. M. Tuinstra, M. O. Aviles, S. Shin et al., "Multifunctional, multichannel bridges that deliver neurotrophin encoding lentivirus for regeneration following spinal cord injury," Biomaterials, vol. 33, pp. 1618-1626, 2012.

[120] H. Itosaka, S. Kuroda, H. Shichinohe et al., "Fibrin matrix provides a suitable scaffold for bone marrow stromal cells transplanted into injured spinal cord: a novel material for CNS tissue engineering," Neuropathology, vol. 29, no. 3, pp. 248-257, 2009.

[121] Y. D. Teng, E. B. Lavik, X. Qu et al., "Functional recovery following traumatic spinal cord injury mediated by a unique polymer scaffold seeded with neural stem cells," Proceedings of the National Academy of Sciences of the United States of America, vol. 99, pp. 3024-3029, 2002.

[122] P. J. Johnson, S. R. Parker, and S. E. Sakiyama-Elbert, "Controlled release of neurotrophin-3 from fibrin-based tissue engineering scaffolds enhances neural fiber sprouting following subacute spinal cord injury," Biotechnology and Bioengineering, vol. 104, no. 6, pp. 1207-1214, 2009.

[123] P. D. Storer, D. Dolbeare, and J. D. Houle, "Treatment of chronically injured spinal cord with neurotrophic factors stimulates $\beta$ II-tubulin and GAP-43 expression in rubrospinal tract neurons," Journal of Neuroscience Research, vol. 74, no. 4, pp. 502-511, 2003. 

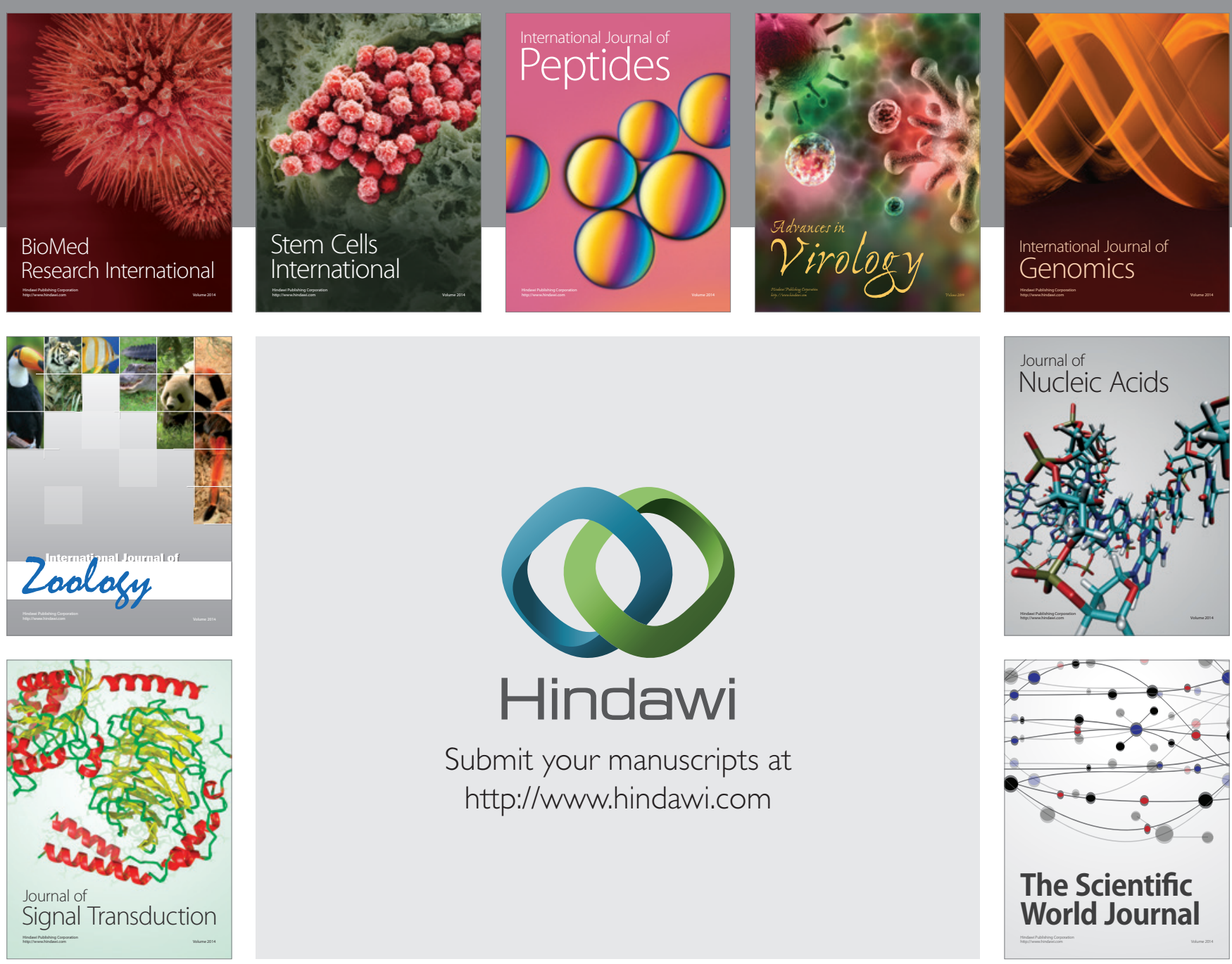

Submit your manuscripts at

http://www.hindawi.com
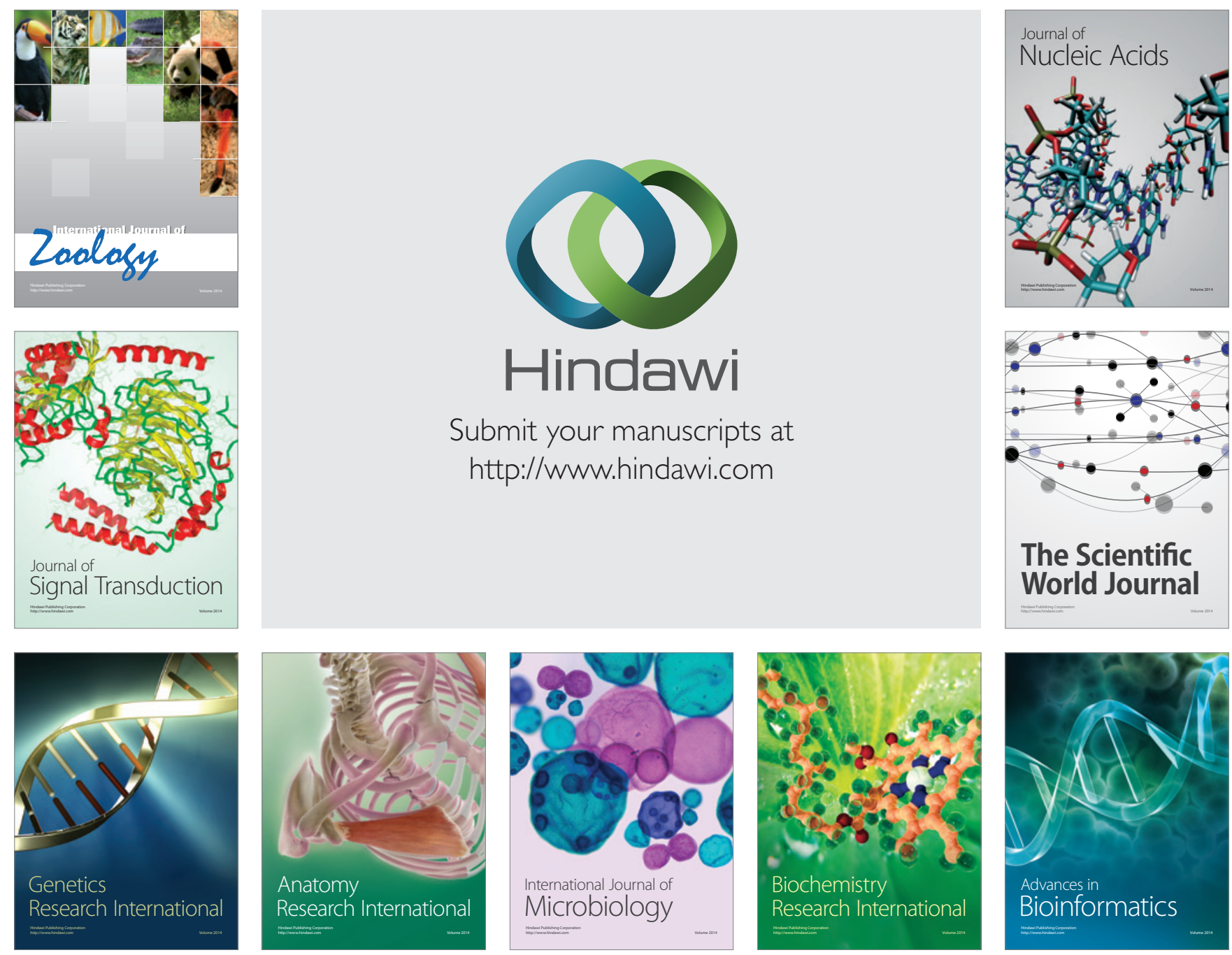

The Scientific World Journal
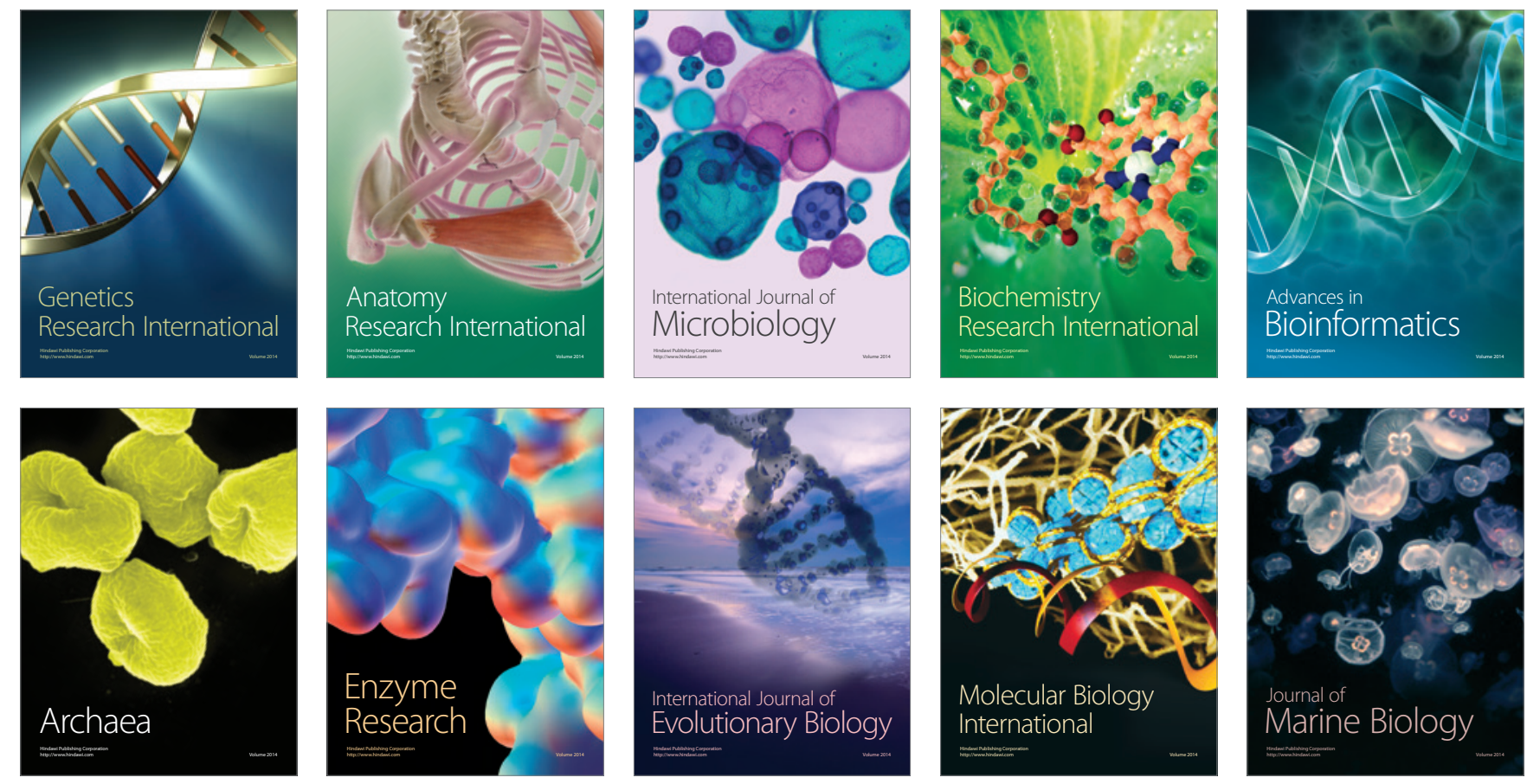